\title{
Expiratory flow limitation in compressed air divers and oxygen divers
}

\author{
K. Tetzlaff*+, L. Friege ${ }^{+}$, M. Reuter++, J. Haber*, T. Mutzbauer, B. Neubauer
}

Expiratory flow limitation in compressed air divers and oxygen divers. K. Tetzlaff, $L$. Friege, M. Reuter, J. Haber, T. Mutzbauer, B. Neubauer. (OERS Journals Ltd 1998.

ABSTRACT: Divers are exposed to dense gases under hyperbaric and hyperoxic conditions and, therefore, may be at risk of developing respiratory disease. Long-term effects on respiratory function have been found in commercial divers who perform deep dives. This study was conducted to detect possible lung function changes in scuba divers who dive in shallow water using compressed air or oxygen as a breathing gas.

A cross-sectional sample of 180 healthy male divers (152 air divers and 28 oxygen divers) and 34 healthy male controls underwent a diving medical examination including body plethysmography, diffusion capacity measurement and a cold-air isocapnic hyperventilation test (CAIH).

Air divers and oxygen divers had a lower mid-expiratory flow at $25 \%$ of vital capacity (MEF25) than controls $(p<0.01$ and $p<0.05$, respectively). Oxygen divers also had a decreased mid-expiratory flow at $50 \%$ of vital capacity $($ MEF50) $(p<0.05)$. Divers' groups and controls did not differ with respect to age, smoking or medical history. The prevalence of airway hyperresponsiveness to CAIH was $1.4 \%$ ( $n=3$ divers). MEF25 and MEF50 were inversely related to years of diving $(p<0.01$ and $p<0.001$, respectively).

The pattern of lung function changes obtained in scuba divers is consistent with small airways dysfunction and the association between diving exposure and lung function changes may indicate long-term effects on respiratory function. Eur Respir J 1998; 12: 895-899.
* Naval Medical Institute of the German Navy, Kiel, Germany. +Depts of Medicine I, ++Psychology and ++Diagnostic Radiology, Christian-Albrechts-University, Kiel, Germany. Federal German Navy Weapons Diver Battalion, Eckernförde, Germany.

Correspondence: K. Tetzlaff

Schiffahrtmedizinisches Institut der Marine

Kopperpahler Allee 120

D-24119 Kronshagen

Germany

Fax: 4943154091778

Keywords: Airflow limitation

diving

hyperbaria

hyperoxia

lung function

Received: November 201997

Accepted after revision June 161998
In underwater diving, the lungs are exposed to hyperoxia at depth and to decompression stress during ascent that involves venous gas microembolism [1]. In addition, submersion, increased gas density and breathing apparatus may adversely affect ventilation in a mechanical way [24]. These factors have been shown to contribute to changes in lung function after deep dives and have indicated the development of respiratory disease due to deep diving $[5,6]$. However, only a few studies have investigated lung function in subjects who dive in shallow water, i.e. $0-50 \mathrm{~m}$ of seawater (msw), with self-contained underwater breathing apparatus (scuba) using compressed air or oxygen as a breathing gas. These diving techniques are used worldwide by an increasing number of sport divers (in Europe there are now about 1 million certified sport divers) and, therefore, it may be worthwhile to assess the relationships between diving and lung function indices with respect to the distinct groups of divers that employ different breathing apparatus.
The aims of the present study were to compare the respiratory function of healthy air divers and oxygen divers with that of healthy controls and to evaluate the association between diving exposure and pulmonary function. The particular hypothesis being tested was that a greater reduction may be expected in oxygen divers, caused by the toxic effects of chronic oxygen exposure on respiratory function.

\section{Methods}

\section{Subjects}

A total of 214 healthy male subjects were investigated during a one-year examination period (table 1). Participation was voluntary and signed informed consent was obtained. The divers were ship divers of the Navy fleet $(n=$

Table 1. - Anthropometric data, endurance sports activities and fractions of smokers and atopics of diving groups and controls

\begin{tabular}{|c|c|c|c|c|c|c|c|}
\hline & $\mathrm{n}$ & $\begin{array}{l}\text { Age } \\
\text { yrs }\end{array}$ & $\begin{array}{l}\text { Height } \\
\mathrm{cm}\end{array}$ & $\begin{array}{c}\text { Weight } \\
\text { kg }\end{array}$ & $\begin{array}{c}\text { Sports } \\
\mathrm{h} \cdot \text { week }^{-1}\end{array}$ & $\begin{array}{c}\text { Smokers } \\
\%\end{array}$ & Atopics \\
\hline Oxygen divers & 28 & $33 \pm 9.1$ & $180 \pm 6.4$ & $80 \pm 6.8$ & $3.6 \pm 2$ & 28.6 & 17.9 \\
\hline Air divers & 152 & $32 \pm 7.7$ & $181 \pm 6.5$ & $84 \pm 11$ & $2.4 \pm 1.8$ & 46.1 & 11.9 \\
\hline Controls & 34 & $29 \pm 8.4$ & $181 \pm 7.1$ & $81 \pm 8.3$ & $2 \pm 1.8$ & 44.1 & 14.7 \\
\hline
\end{tabular}

Values are means \pm SD. 
152) exclusively employing open-circuit compressed air diving apparatus (Draeger ASG 2800, Luebeck, Germany) and combat divers from the Combat Swimmers Platoon $(n=28)$ using closed-circuit oxygen rebreathing apparatus (Draeger LAR V). Air divers were consecutively selected by attendance for the regular Navy diving medical examination, which is performed at intervals of 1-3 yrs at the authors' department. At least one-half of the total Navy ship diver population was investigated. Moreover, all combat swimmers of the Navy were included in the study. All subjects passed the pulmonary fitness criteria, whereas eight subjects who had been found to be temporarily unfit to dive for other reasons (e.g. inability to equalize pressure during the hyperbaric chamber test) were also included in the lung function study. Diving experience was assessed by means of log-book documented years of diving, the total number of dives and the total number of hours under water. Recreational diving experience was assessed by questionnaire and added to military exposure indices. Mean maximum depth was not assessed because all subjects had performed dives within the limits of the military diving depth range, which allows compressed air dives to a maximum depth of $60 \mathrm{msw}$. Oxygen divers had a higher level of diving experience, as indicated by means of years of diving, number of dives and hours of diving (table 2). However, differences between divers' groups did not reach statistical significance with respect to these variables. Diving variables were significantly interrelated $(\mathrm{p}<0.01)$. The control subjects $(n=34)$ were recruited from board personnel of the Navy fleet. They had no experience in either military or recreational diving. Sports activities per week, smoking habits and a history of nasal allergy were as-sessed by questionnaire. Exsmokers were classified as nonsmokers if they had refrained from smoking for $>5 \mathrm{yrs}$. One-way analysis of variance (ANOVA) revealed no significant differences between groups (oxygen divers versus air divers versus controls) with respect to age, height and weight (table 1). Moreover, the groups did not differ significantly in either the fraction of smokers or the number of cigarettes smoked daily. The distribution of nasal allergy among subjects in the three groups likewise revealed no significant differences among groups. Oxygen divers performed endurance sports significantly more frequently than air divers and controls $(\mathrm{p}=0.003$ and $\mathrm{p}=0.001$, respectively).

\section{Lung function tests}

Lung function testing was performed using a computerized pneumotachography system (Jaeger Masterlab, Wuerzburg, Germany). A whole-body plethysmograph served for measurement of airway resistance (Raw). According to the

Table 2. - Diving indices of divers' samples

\begin{tabular}{lccc}
\hline & $\begin{array}{c}\text { Years } \\
\text { diving }\end{array}$ & $\begin{array}{c}\text { Hours } \\
\text { diving }\end{array}$ & $\begin{array}{c}\text { Total } \\
\text { dives }\end{array}$ \\
\hline Oxygen divers & $10.5(1-34)$ & $257(17-5000)$ & $351(20-6310)$ \\
Air divers & $7(1-32)$ & $200(7-4000)$ & $244(6-5500)$ \\
\hline
\end{tabular}

Values are medians with range in parenthesis. method recommended by Quanjer et al. [7], subjects sat inside a chamber and breathed through a tube that was connected to a heated pneumotachometer. The nose was closed by a clip. Raw was computed from the ratio between pressure drop and the flow at the mouth during panting. The mean of five satisfactory measurements was reported. Intrathoracic gas volume (IGV) was calculated from the relationship between pressure changes at the mouth and inside the chamber induced by airway occlusion during insp- iration and expiration. Specific airway resistance (sRaw) was derived from the multiplication of IGV by $R$ aw. The measurement of functional residual capacity combined with expiratory and inspiratory reserve volume manoeuvres served for the calculation of residual volume (RV). Total lung capacity (TLC) was derived from RV and inspiratory vital capacity (IVC). Spirometry was used to assess static and dynamic lung volumes as well as flow rates. IVC, forced vital capacity (FVC), forced expiratory volume in one second (FEV1), peak expiratory flow (PEF) as well as expiratory flow rates at $75 \%, 50 \%$ and $25 \%$ of FVC (MEF75, MEF50, MEF25) were taken as the best of three voluntary manoeuvres with FVC not differing by more than $5 \%$ from its highest value.

The transfer factor of the lung for carbon monoxide ( $T$ L,CO) was measured using the single breath technique according to the method recommended by CoTES et al. [8]. Subjects were seated and inhaled a gas mixture of $0.27 \%$ $\mathrm{CO}, 9.27 \% \mathrm{He}$ and $21 \% \mathrm{O}_{2}$. TL, CO was derived from changes in gas concentration after a 10 second breath hold. The obtained values were corrected to a haemoglobin concentration of $14.6 \mathrm{~g} \cdot \mathrm{dL}^{-1}$. Effective alveolar volume $(V \mathrm{~A})$ was measured simultaneously by He dilution and transfer per unit effective alveolar volume $(T \mathrm{~L}, \mathrm{CO} / V \mathrm{~A})$ was calculated.

A cold air challenge was performed according to the procedure described by Assourl et al. [9] using a single-step four minute isocapnic hyperventilation. Subjects were seated and inspired cold air (inspired air temperature -12 to $-15^{\circ} \mathrm{C}$ ) through a heat exchanger (Jaeger RHES, Wuerzburg, Germany). Carbon dioxide was added by flow to maintain $5 \%$ in the inspired air. The target minute ventilation was $70-80 \%$ of maximal voluntary ventilation, which was maintained by instructing the subject to keep the reservoir bag filled. The test was terminated after $4 \mathrm{~min}$ of isocapnic hyperventilation. Postchallenge lung function was assessed by spirometry. In any case of airway hyperresponsiveness (AHR) following a challenge test broncholysis with fenoterol was applied and terminal lung function controlled for reversibility.

\section{Chest radiography}

Sixteen subjects had undergone chest radiography elsewhere and written statements on normal findings were accepted as an assessment of their fitness to dive. In 198 subjects chest radiography was performed at the authors' department and evaluated by a suitably qualified thoracic radiologist (M. Reuter) who was blinded to diving history. In particular, secondary signs of overinflation of the lung were evaluated according to a schedule proposed by FRASER et al. [10]. 


\section{Procedure}

All subjects underwent a diving fitness examination according to the Navy regulations that included medical history and physical examination. None had prior or current lung diseases. The lung function tests were conducted in the morning between 08:00 and 09:00 $\mathrm{h}$ to avoid effects of diurnal variation. Pressure calibration of the body chamber, calibration of the gas analysers and volume calibration of the spirometer were performed daily before pulmonary function testing. The subjects had refrained from smoking for at least $2 \mathrm{~h}$ before pulmonary function testing.

\section{Statistical analyses}

Lung function variables (means of totals and percentages of predicted) were compared between groups (oxygen divers versus compressed air divers versus controls and, within a second step, divers versus controls) by MannWhitney U-tests. Because of the great differences between sample sizes the correction formulae provided by VERDOOREN [11] were used when testing air divers versus controls and air divers versus oxygen divers, respectively. Chi-squared tests were applied for comparison of nominal data (nasal allergy yes/no, smoking yes/no) between groups (oxygen divers versus compressed air divers versus controls). Stepwise forward multiple linear regression analysis was performed to assess the association between lung function variables and diving variables (years of diving, number of dives and hours of diving). A logarithmic transformation of the diving variables was used in the analysis because these variables were not normally distributed. Pearson's correlations were applied to detect interrelationships between diving variables. A p-value $<0.05$ was considered significant. Analyses were performed using the SPSS statistical software package (SPSS Inc., Chicago, IL, USA).

\section{Results}

Comparison of lung function values between groups (air divers versus oxygen divers versus controls) revealed significant differences with respect to expiratory flow rates at low lung volumes and diffusion capacity only (table 3). Expiratory flow rates MEF50 and MEF25 were lower in divers than in controls. The differences between groups (air divers versus controls and oxygen divers versus controls) reached significance with respect to MEF25 ( $p<0.01$ and $p=0.01$, respectively). MEF50 was significantly lower in oxygen divers than in controls $(p<0.05)$. Prechallenge FEV1 was lower in oxygen divers than in controls, but this difference was not significant $(\mathrm{p}=0.051$ ). $T \mathrm{~L}, \mathrm{CO} / V \mathrm{~A}$ was significantly higher in oxygen divers than in air divers, whereas no significant difference emerged when compared with controls. Comparison of lung function values between divers as a whole group $(n=180)$ and controls revealed a lower $\mathrm{MEF}_{25}(\mathrm{p}<0.01)$ in divers.

Multiple regression analysis of lung function on diving exposure revealed positive correlations between years of diving and FVC, IVC, TLC, TL,CO $(\mathrm{p}<0.05)$ and $V \mathrm{~A}(\mathrm{p}<$ $0.01)$. The increase in these variables also depended on height $(\mathrm{p}<0.001)$, whereas age $(\mathrm{p}<0.001)$ and smoking $(\mathrm{p}<$ 0.01 ) correlated negatively. MEF25 and MEF50 declined with years of diving $(\mathrm{p}<0.01$ and $\mathrm{p}<0.001$, respectively) independent of smoking but for MEF25 the reduction was exacerbated by age $(\mathrm{p}<0.05)$.

A significant response to cold air with a $>10 \%$ decline in FEV 1 following cold air isocapnic hyperventilation (CAIH) was found in three subjects only, all of whom were divers. Thus, the prevalence of AHR amounted to $1.66 \%$ in the divers' sample and to $1.4 \%$ in the whole population studied.

Evaluation of chest radiographs revealed nine air divers, three oxygen divers and three control subjects who presented with subtle secondary radiographic signs of pulmonary overinflation (flattened configuration of the dia-

Table 3. - Details of lung function parameters of diving groups and controls

\begin{tabular}{|c|c|c|c|}
\hline & $\begin{array}{l}\text { Air divers } \\
(\mathrm{n}=152)\end{array}$ & $\begin{array}{l}\text { Oxygen divers } \\
(\mathrm{n}=28)\end{array}$ & $\begin{array}{l}\text { Controls } \\
(\mathrm{n}=34)\end{array}$ \\
\hline$\overline{\mathrm{FVC} \mathrm{L}}$ & $5.6 \pm 0.72$ & $5.5 \pm 0.74$ & $5.8 \pm 0.69$ \\
\hline IVC L & $5.6 \pm 0.67$ & $5.6 \pm 0.64$ & $5.7 \pm 0.68$ \\
\hline TLC L & $7.8 \pm 1.12$ & $7.8 \pm 0.83$ & $7.7 \pm 0.94$ \\
\hline RV L & $2.1 \pm 0.74$ & $2.1 \pm 0.56$ & $1.9 \pm 0.47$ \\
\hline IGV L & $3.8 \pm 0.73$ & $3.9 \pm 0.62$ & $3.9 \pm 0.94$ \\
\hline FEV1prechallenge $\mathrm{L}$ & $4.7 \pm 0.63$ & $4.6 \pm 0.70$ & $5.0 \pm 0.75$ \\
\hline FEV1postchallenge $\mathrm{L}$ & $4.8 \pm 0.63$ & $4.7 \pm 0.69$ & $4.9 \pm 0.77$ \\
\hline $\mathrm{PEF} \mathrm{L} \cdot \mathrm{s}^{-1}$ & $11.2 \pm 1.94$ & $10.7 \pm 1.99$ & $10.7 \pm 1.96$ \\
\hline MEF75 L $\cdot \mathrm{s}^{-1}$ & $9.1 \pm 1.92$ & $8.5 \pm 2.10$ & $9.1 \pm 2.06$ \\
\hline MEF50 $\mathrm{L} \cdot \mathrm{s}^{-1}$ & $5.4 \pm 1.32$ & $5.1 \pm 1.45^{*}$ & $5.9 \pm 1.56$ \\
\hline $\mathrm{MEF} 25 \mathrm{~L} \cdot \mathrm{s}^{-1}$ & $2.2 \pm 0.70 * *$ & $2.1 \pm 0.85^{*}$ & $2.7 \pm 0.77$ \\
\hline$R$ aw $\mathrm{kPa} \cdot \mathrm{s}^{-1} \cdot \mathrm{L}^{-1}$ & $0.260 \pm 0.008$ & $0.262 \pm 0.006$ & $0.257 \pm 0.008$ \\
\hline $\mathrm{s} R$ aw $\mathrm{kPa} \cdot \mathrm{s}^{-1}$ & $1.04 \pm 0.24$ & $1.13 \pm 0.26$ & $1.1 \pm 0.29$ \\
\hline$T \mathrm{~L}, \mathrm{CO} \quad \mathrm{mmol} \cdot \mathrm{min}^{-1} \cdot \mathrm{kPa}^{-1}$ & $10.9 \pm 1.87$ & $11.4 \pm 1.80$ & $11.6 \pm 1.62$ \\
\hline$T \mathrm{~L}, \mathrm{CO} / V_{\mathrm{A}} \mathrm{mmol} \cdot \mathrm{min}^{-1} \cdot \mathrm{kPa}-1 \cdot \mathrm{L}^{-1}$ & $1.50 \pm 0.20$ & $1.58 \pm 0.18$ & $1.6 \pm 0.24$ \\
\hline$V \mathrm{~A} L$ & $7.3 \pm 1.08$ & $7.2 \pm 0.8$ & $7.4 \pm 1.09$ \\
\hline
\end{tabular}

Values are means \pm SD. *: $\mathrm{p}<0.05$ versus controls; $* *: \mathrm{p}<0.01$ versus controls; $; \mathrm{p}<0.05$ versus air divers. FVC: forced vital capacity; IVC: inspiratory vital capacity; TLC: total lung capacity; RV: residual volume; IGV: intrathoracic gas volume; FEV1: forced expiratory volume in one second; PEF: peak expiratory flow; MEF75, MEF50, MEF25: mid-expiratory flow at 75\%, 50\% and 25\% of vital capacity, respectively; Raw: airway resistance; $\mathrm{s} R$ aw: specific airway resistance; $T \mathrm{~L}, \mathrm{CO}$ : transfer factor of the lung for carbon monoxide; $V \mathrm{~A}$ : alveolar volume. 
phragm, increase in depth of the retrosternal air space, anterior bowing of the sternum, increased thoracic kyphosis and long vertical configuration of the cardiovascular contur). Only three subjects had two or more signs of overinflation.

\section{Discussion}

The principal finding of this study was a reduction in expiratory flow rates at low lung volumes in scuba divers compared with nondiving controls, indicating the development of small airway dysfunction. Previous cross-sectional studies of lung function changes in compressed air divers either did not assess detailed dynamic lung function [12] or failed to detect an association between diving indices and lung function [13]. In a longitudinal study of 20 professional compressed air divers BERMON et al. [14] obtained a pronounced decrease in expiratory flows over time but could not detect a relation between lung function and diving indices.

A pattern of lung function changes that compares favourably to the present results, however, has been reported from studies that involved commercial saturation divers, who represent a special group of divers who perform deep dives (mean maximum depth $>100 \mathrm{msw}$ ) and are exposed to particular working environments [6]. THORSEN et al. [15] found significantly lower expiratory flow rates and a reduced pulmonary diffusion capacity in a cross-sectional study of 152 Norwegian commercial divers compared with 100 healthy control subjects. Likewise, ElLIoTt et al. [16], in a cross-sectional sample of 115 British commercial divers, and DAvEY et al. [17], in a longitudinal sur- vey of 81 commercial divers, obtained reduced expiratory flow rates in divers. Years of diving was found to correlate with a decline in expiratory flows. The authors interpreted their results within the framework of narrowing of small airways due to diving. In the divers in the present study, the decline in expiratory flows MEF25 and MEF50 was significantly related to years of diving. Years of diving was the only diving index that satisfactorily predicted lung function variables. The possibility remains, however, that the indices of diving exposure used here and in the literature are not accurate enough.

The reduction in expiratory flow rates was greater in oxygen divers than in air divers. This may be attributed to the higher cumulative oxygen exposure, since inspiratory oxygen pressure $\left(P \mathrm{I}, \mathrm{O}_{2}\right)$ is elevated during oxygen diving, which is usually performed within a $0-7 \mathrm{msw}$ depth range, up to $100-170 \mathrm{kPa}$. It is widely recognized that long-term exposure to $\mathrm{P}, \mathrm{O}_{2} \breve{S} 50 \mathrm{kPa}$ produces mild to severe toxic effects and that the severity of oxygen poisoning increases with elevation of the $P \mathrm{I}, \mathrm{O}_{2}$ [18]. However, since intermittent hyperoxic exposure entails recovery from adverse effects on pulmonary function [18], exposures to a $\mathrm{PI}, \mathrm{O}_{2}$ of $175 \mathrm{kPa}$ for $2 \mathrm{~h}$ daily, which meets the exposure in oxygen diving, are considered not to result in persistent lung damage [19]. The decrease in MEF50 and MEF25 obtained in the oxygen divers certainly indicates adverse effects after cumulative oxygen diving exposure. However, the observed differences between divers and controls with respect to expiratory flows are relatively small and lie within the normal range when compared with the predicted standard values from normal population samples.

THORSEN et al. [15] showed a significant reduction in $T \mathrm{~L}, \mathrm{CO}$ in commercial divers compared with nondiving controls. According to the results of BERMON et al. [14], the $T \mathrm{~L}, \mathrm{CO}$ and $T \mathrm{~L}, \mathrm{CO} / V \mathrm{~A}$ of the present divers were within the predicted normal range. However, oxygen divers had a significantly higher TL,CO than compressed air divers. Since $T \mathrm{~L}, \mathrm{CO}$ is negatively related to smoking, the higher fraction of smokers among compressed air divers may account for this difference.

The validity of increased translucency as a radiographic sign of pulmonary overinflation is questionable, particularly in, divers, who tend to be healthy young males with a large TLC. For this reason evaluation of chest radiographs relied primarily on secondary signs of overinflation. However, mildly affected lungs are usually considered free of hyperinflation whatever the criteria used in plain film radiology. Therefore, the largely normal plain film findings observed in this study are not unexpected. Future prospective studies on this topic should include highresolution computed tomography of the lungs supplemented by scans obtained at end-expiration [20].

In conclusion, the reduction in expiratory flows at low lung volumes concurs with previous findings in commercial deep diving and may indicate adverse long-term health effects on respiration, even of scuba diving in shallow water. However, there was no evidence of chronic respiratory disease from the evaluation of chest radiographs. Longitudinal surveys will be necessary to prove whether the lung function changes become pronounced with further exposure to scuba diving.

\begin{abstract}
Acknowledgements: The authors are grateful to the following people for their invaluable assistance: J. Weimar, Surg Cdr (US Navy), Percy McCormack and the subjects of this study. The opinions herein stated are the private ones of the authors and cannot be regarded as the official opinions of the Federal German Navy or the German Ministry of Defence.
\end{abstract}

\section{References}

1. Vann RD. Mechanisms and risks of decompression. In: Bove AA, Davis JC, eds. Diving Medicine. Philadelphia, PA, Saunders, 1990; pp. 29-49.

2. Agostini E, Gurtner G, Torri G, Rahn H. Respiratory mechanics during submersion and negative pressure breathing. J Appl Physiol 1966; 21: 251-258.

3. Van Liew HD. Mechanical and physical factors in lung function during work in dense environments. Undersea Biomed Res 1983; 10: 255-264.

4. Flook V. Basic respiratory physiology. In: Flook V, Brubakk AO, eds. Lung Physiology and Divers' Breathing Apparatus. Flagstaff, AZ, Best Publishing, 1992; pp. 112.

5. Elliott DH, Moon RE. Long-term health effects of diving. In: Bennett PB, Elliott DH, eds. The Physiology and Medicine of Diving. 4th Edn. London, Saunders, 1993; pp. 585-604

6. Cotes JE. Respiratory effects of diving. Eur Respir $J$ 1994; 7: 2-3.

7. Quanjer PH, Tammeling GJ, Cotes JE, Pedersen OF, Peslin R, Yernault JC. Lung volumes and forced expiratory 
flows. Report working party standardization of lung function tests European Community for Steel and Coal. Eur Respir J 1993; 6: Suppl. 16, 5-40.

8. Cotes JE, Chinn DJ, Quanjer PH, Roca J, Yernault JC. Standardization of the measurement of transfer factor (diffusing capacity). Report working party standardization of lung function tests European Community for Steel and Coal. Eur Respir J 1993; 6: Suppl. 16, 41-52.

9. Assoufi BK, Dally MB, Newman-Taylor AJ, Denison DM. Cold air test: a simplified standard method for airway reactivity. Bull Eur Physiopathol Respir 1986; 22: 349-357.

10. Fraser RG, Pare JAP, Pare PD, Fraser RS, Genereux GP. Diagnosis of diseases of the chest. 3rd Edn. Philadelphia, PA, Saunders, 1988; pp. 639-663.

11. Verdooren LR. Extended tables of critical values for Wilcoxon's test statistics. Biometrika 1963; 50: 177-186.

12. Clifford GM, Smith DJ, Searing CSM. A comparison of lung volumes between divers and submariners in the Royal Navy. J R Nav Med Serv 1984; 70: 143-148.

13. Dembert ML, Beck GJ, Jekel JF, Mooney LW. Relations of smoking and diving experience to pulmonary function among U.S. Navy divers. Undersea Biomed Res 1984; 11: 299-304.
14. Bermon S, Lapoussiere JM, Dolisi C, Wolkiewiez J, Gastaud M. Pulmonary function of a firemen-diver population: a longitudinal study. Eur J Appl Physiol 1994; 69: 32-35.

15. Thorsen E, Segadal K, Kambestad BK, Gulsvik A. Divers' lung function: small airways disease? $\mathrm{Br} J$ Ind Med 1990; 47: 519-523.

16. Elliott C, Reed JW, Cotes JE, Robinson NG, King J. Narrowing of small lung airways in commercial divers. In: Sterk W, Geeraedts L, eds. Proceedings of the European Underwater Hyperbaric Biomedical Society. Amsterdam, EUBS, 1990; pp. 197-202.

17. Davey IS, Cotes JE, Reed M. Relationship of ventilatory capacity to hyperbaric exposure in divers. J Appl Physiol 1984; 56: 1655-1658.

18. Clark JM. Oxygen toxicity. In: Bennett PB, Elliott DH, eds. The Physiology and Medicine of Diving. 4th Edn. London, Saunders, 1993; pp. 121-169.

19. Donald KW. Oxygen and the Diver. Harley Swan UK, SPA, 1992.

20. Stern EJ, Webb WR, Gamsu G. Dynamic quantitative computed tomography. A predictor of pulmonary function in obstructive lung diseases. Invest Radiol 1994; 29: 564-569. 